\title{
Structure and Antioxidant Catalytic Function of Plant Glutathione Trans- ferases
}

\author{
Evangelia Chronopoulou ${ }^{1}$, Irene Axarli ${ }^{1}$, Irini Nianiou-Obeidat ${ }^{2}$, Panagiotis Madesis ${ }^{3}$, Athanasios \\ Tsaftaris $^{2,3}$ and Nikolaos E. Labrou ${ }^{1 *}$
}

\author{
${ }^{1}$ Laboratory of Enzyme Technology, Department of Agricultural Biotechnology, Agricultural University of Athens, Iera \\ Odos 75, 11855-Athens, Greece; ${ }^{2}$ Department of Genetics and Plant Breeding, School of Agriculture, Aristotle Univer- \\ sity of Thessaloniki, P.O. Box 261, Thessaloniki GR-54124, Greece.; ${ }^{3}$ Institute of Agrobiotechnology, CERTH, 6th $\mathrm{km}$ \\ Charilaou-Thermis Road, P.O. Box 361, Thermi GR-57001,Thessaloniki, Greece
}

\begin{abstract}
Plant cytosolic glutathione transferases (GSTs) are an ancient enzyme superfamily with multiple and diverse functions which are important in counteracting biotic and abiotic stress. GSTs play an important role in catalyzing the conjugation of xenobiotics and endogenous electrophilic compounds with glutathione (GSH), such as pesticides, chemical carcinogens, environmental pollutants, which leads to their detoxification. GSTs not only catalyze detoxification reactions but they are also involved in GSH-dependent isomerization reactions, in GSH-dependent reduction of organic hydroperoxides formed during oxidative stress, biosynthesis of sulfur-containing secondary metabolites, and exhibit thioltransferase and dehydroascorbate reductase activity. This review focuses on plant GSTs, and attempts to give an overview of the new insights into the catalytic function and structural biology of these enzymes.
\end{abstract}

keywords: Glutathione transferase, herbicide detoxification, biotic stress, abiotic stress.

\section{INTRODUCTION}

GSTs are ubiquitous enzymes in aerobic organisms and are encoded by large gene families of cytosolic, mitochondrial, and microsomal proteins. GSTs catalyze the conjugation of reduced glutathione ( $\gamma$-L-Glu-L-Cys-Gly; GSH) via the sulfhydryl group, to electrophilic centers on a wide variety of compounds, both endogenous and xenobiotic [1-4]. The conjugation of GSH to these endogenous compounds serves several important roles: (a) limit and restrict the reactivity of the chemicals; (b) increases their solubility and facilitates their membrane transport and elimination from the cell and organism; and (c) in some cases, it leads to the formation of secondary metabolites or essential biological mediators $[1,5]$.

The GSTs comprise a complex enzyme superfamily that has been subdivided into a number of classes based on a variety of criteria (e.g. amino acid/nucleotide sequence, and immunological, kinetic and structural properties) [6]. GST genes and proteins from mammalian sources have been well characterized, but studies of GSTs from non-mammalian sources such as plants and microorganisms have revealed the existence of several different classes (for more details see Sheehan et al., 2001 [6]). For example, the plant soluble GSTs according to their sequence relatedness, immunological cross reactivities, kinetic properties and genome organizations can be subdivided into the following distinct classes:

\footnotetext{
*Address correspondence to this author at the Laboratory of Enzyme Technology, Department of Agricultural Biotechnology, Agricultural University of Athens, Iera Odos 75, 11855-Athens, Greece; Tel/Fax: +30 2105294308 ; E-mail: lambrou@aua.gr
}

phi $(\mathrm{F})$, tau $(\mathrm{U})$, zeta $(\mathrm{Z})$, theta $(\mathrm{T})$, lambda $(\lambda)$, dehydroascorbate reductase (DHAR), and tetrachlorohydroquinone dehalogenase (TCHQD) [4-10]. The majority of the plant GSTs belongs to the tau (GSTU) and phi (GSTF) classes, which are plant specific.

GSTs are known as promiscuous enzymes capable of catalyzing the conjugation of GSH with a broad range of electrophilic substrates [11-13]. GSTs exhibit wide substrate specificity toward electrophile molecules including organic halides, organic hydroperoxides, epoxides, arene oxides, $\alpha$ and $\beta$-unsaturated carbonyls, organic nitrate esters, and organic thiocyanates [14]. GSTs not only catalyze the conjugation of GSH to electrophilic compounds but they also have more functions. For example, some members are involved in GSH-dependent isomerization reactions (e.g. in GSHdependent isomerization of maleylacetoacetate to fumarylacetoacetate), in the synthesis of sulfur-containing secondary metabolites such as volatiles and glucosinolates, and the conjugation, transport and storage of reactive oxylipins, phenolics and flavonoids [5]. It is widely assumed that the functional promiscuity of GSTs correlates with structural flexibility, which allows for recognition of diverse structures at minimal energetic cost [15]. Typical GST-catalyzed reactions are schematized in Fig. (1).

GSTs play a crucial role in the protection of cells from a wide range of biotic and abiotic stresses, including pathogen attack, xenobiotic and heavy metal toxins, oxidative stress and UV radiation [16-20]. Their role in stress tolerance in plants is less characterized than their detoxification function [21], however, GSTs are thought to be evolved as part of the cell protection system against oxygen toxicity $[22,23]$. The 


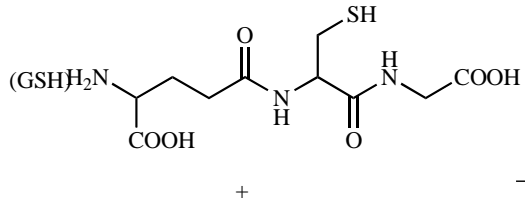

(Xenobiotic)

$\mathrm{R}-\mathrm{X}$<smiles>[R]CC(NC(=O)CCC(N)C(=O)O)C(=O)NCC(=O)O</smiles><smiles>NC(CCC(=O)NC(CS)C(=O)NCC(=O)O)C(=O)NCC(=O)NC(CSc1ccc([N+](=O)[O-])cc1[N+](=O)[O-])C(=O)NCC(=O)O</smiles><smiles>C=C(CC)C(=O)c1ccc(OCC(=O)O)c(Cl)c1Cl</smiles><smiles>CCC(CS)C(=O)c1ccc(OCC(=O)O)c(Cl)c1Cl</smiles><smiles>NC(CCC(=O)NC(CS)C(=O)NCC(=O)O)C(=O)O</smiles><smiles>CCC(NC(=O)CCC(N)C(=O)O)C(=O)NCC(=O)O</smiles><smiles>CC(C)(OO)c1ccccc1</smiles><smiles>NC(CCC(=O)NC(CS)C(=O)NCC(=O)O)C(=O)O</smiles><smiles>C1CCCCC1</smiles><smiles>CC(C)(O)c1ccccc1</smiles><smiles>NC(CCC(=O)NC(CSSCC(NC(=O)CCC(N)C(=O)O)C(=O)NCC(=O)O)C(=O)NCC(=O)O)C(=O)O</smiles>

Fig. (1). A: Glutathione conjugation to a generic xenobiotic (X) catalyzed by a GST, results in the formation of a glutathione-S conjugate. B: Typical GST-catalyzed reactions. (1): nucleophilic aromatic substitution with 1-chloro-2,4-dinitrobenzene, (2): Michael-type addition reaction with ethacrynic acid, (3): hydroperoxide reduction with cumene hydroperoxide. 


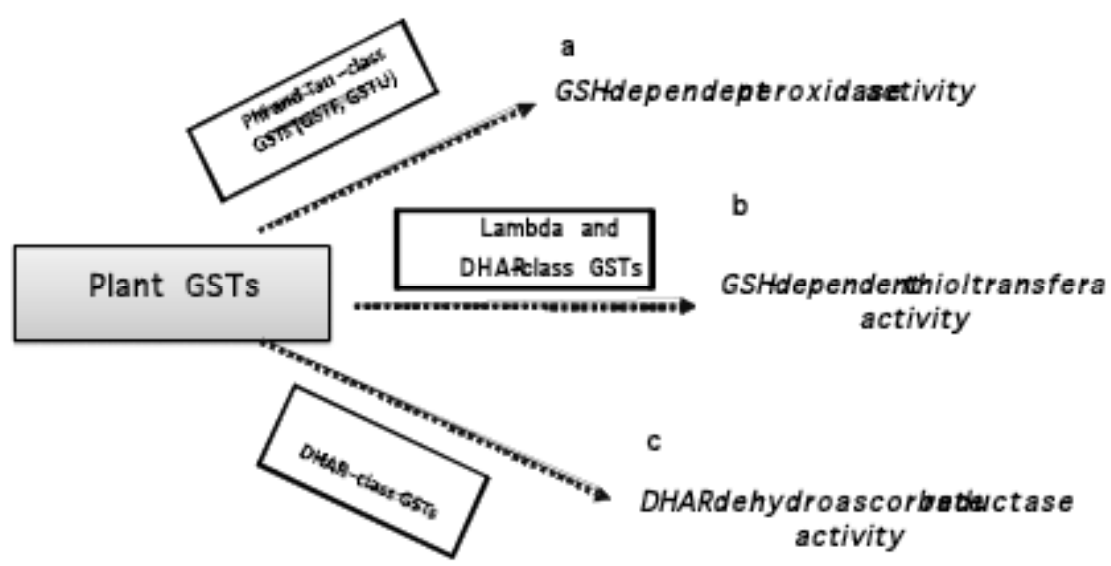

Fig. (2). Catalytic activity in relation to the antioxidant function of GSTs: a) peroxidase activity, b) GSH-dependent thioltransferase activity, and c) dehydroascorbate reductase activity.

antioxidant catalytic function of GSTs [9] is displayed through peroxidase (GPxs) [24], thioltransferase and dehydroascorbate reductase activity [21,25,26] (Fig. 2).

Proteins able to participate in unrelated biological processes have been grouped under the generic name of moonlighting proteins $[27,28]$. Work with different organisms has uncovered a great number of GST isoenzymes that are able to participate in unrelated biological processes. In addition to their role in catalyzing the conjugation of electrophilic substrates to GSH, these enzymes also carry out a range of other functions. Different activities of GST isoenzymes include their role as modulators of signal transduction pathways that control cell proliferation and cell death, regulation of the metabolic pathways, bind non-catalytically and transfer a wide range of endogenous and exogenous ligands [5,6,29,30,31]. For example, the isoenzyme GSTP1-1 from human is an ubiquitously expressed protein that plays an important role in the detoxification and xenobiotics metabolism. This isoenzyme, has been associated with the development of tumor resistance to anticancer drugs, acts as a repressor of JNK and other protein kinases involved in stress response, cell proliferation, and apoptosis, and plays an important regulatory role in TNF- $\alpha$-induced signaling by forming ligand-binding interactions with TRAF2 [32,33]. Another example of moonlight activity comes from the protein Ure2 [34]. Ure2 is an important regulator of nitrogen catabolite repression, the process that controls the utilization of available nitrogen sources by $S$. cerevisiae. Ure2 does not have a typical GST substrate specificity but belongs to a subset of GST proteins that exhibits glutathione peroxidase activity and are active against different oxidants [35].

\section{ANTIOXIDANT CATALYTIC FUNCTION OF GSTs}

GSH can function as an antioxidant and as a substrate or cofactor of GSTs [7,36-41]. GSH is mainly known for its antioxidant function against Reactive Oxygen Species (ROS) and hydrogen peroxide $\left(\mathrm{H}_{2} \mathrm{O}_{2}\right)[42,43]$. The high concentration of ROS can lead to a non-controlled oxidation of DNA, proteins and membrane lipids which can cause disruption of metabolism and cellular structure destruction $[41,44]$.

Plant GSTs exhibit GSH-dependent peroxidase activity (GPx , EC 1.11.1.9) [24,45] and act protectively against cy- totoxicity by reducing organic hydroperoxides of fatty acids and nucleic acids to monohydroxyalcohols which are less toxic $[1,10,25]$. This reaction is important as prevents the formation of cytotoxic aldehyde derivatives from organic hydroperoxides degradation [10].

Plant GSTs with GPx activity contribute to defence against oxidative injury during various stresses, including oxidative stress, pathogen attack, herbicide treatment, and to abiotic stresses [46]. It was suggested that in addition to the direct protective effect of the GPx activity, the enhanced tolerance may be due to the GPx-mediated increase in GSSG concentration in the cells, which then function as a signal to activate further protective stress responses [47-49].

The GPxs in plants can be divided into three types. These are the selenium-dependent GPxs identified in Aloe vera [50], the non-selenium dependent phospholipids hydroperoxide glutathione peroxidases (PHGPxs) and glutathione transferases showing glutathione peroxidase activity [51]. The selenium-dependent GPxs composed of four $16 \mathrm{kDa}$ subunits contain selenocysteine at the catalytic site and appears to be similar to mammalian cytosolic GPx. PHGPx contain cysteine at the catalytic site and appears to be different to the mammalian type PHGPxs. These enzymes can be widely found in plant cells including chloroplasts, mitochondria, cytoplasm, peroxisome and apoplast [51-53].

Plant theta and tau class GSTs exhibit high GPx activities toward organic hydroperoxides [54]. For example, the isoenzymes from wheat [16], peas [8], soybean [55], monocot weeds such as Alopecurus myosuroides (blackgrass), and dicot weeds such as Arabidopsis thaliana [51,56] display wide substrate specificity towards organic hydroperoxides. In particular, the phi and tau class GSTs from Arabidopsis thaliana have shown high peroxidase activity with linoleic acid hydroperoxides (13-hydroperoxy-9,11,15octadecatrienoic acid and 13-hydroperoxy-9,11octadecadienoic acid) [56].

The isoenzymes of the GST-like class with dehydroascorbate reductase (DHAR) activity catalyze the reduction of dehydroascorbate (DHA) to ascorbic acid using_GSH. Members of this class have already been found in Arabidopsis [9], rice and soybean [21]. The DHARs do not exhibit 
GSH conjugating activity. Unlike most other GSTs, DHARs are monomeric and form mixed disulfides with GSH [9].

Members of the lambda and DHARs classes of GSTs, exhibit thioltransferase activity using the 2-hydroxyethyl disulfide (HED) as a substrate [9]. In cases of oxidative stress, when there is a lack of GSH, some protein thiols are S-thiolated making protein-thiol disulfides (Fig. 3). This modification affects the activity of the proteins or enzymes. Whereas many proteins are active when the key sulfhydryls are in the thiol form, others require them to be in the oxidized, disulfide form [57,58]. For example, glutathione disulfide (GSSG) can activate enzymes such as glucose-6phosphatase, acid phosphatase, $\gamma$-aminolaevulinate synthetase, creatine kinase, etc. On the other hand, glutathione disulfide inhibits glycogen synthetase, pyruvate kinase, adenylate cyclase, phosphorylase/phosphatase, ribonucleotide reductase, phosphofructokinase, etc $[10,57,59,60,61]$.

\section{STRUCTURE OF GSTS}

GSTs belong to the thioredoxin superfamily (also including thioredoxin, glutaredoxin, and disulfide-bond formation facilitator) classified by the common GSH binding domainadopted thioredoxin fold (Fig. 4) [62,63]. So far, the available three-dimensional (3D) that have been solved can be summarized as follows: (i) one phi class GSTs from Arabodopsis thaliana [64], two from maize (ZmGSTF1 and ZmGSTF3) [65,66], (ii) a zeta class GST from Arabodopsis thaliana [67], (iii) and three tau class GSTs, one from wheat ( $T a$ GSTU4) active in herbicide detoxification [19], one from rice (OsGSTU1), and more recently one from Glycine max (GmGSTU4-4) [68,69]. Because of the important role of the tau class GSTs, the structure of the GmGSTU4-4 [68,69] will be presented and discussed with regards to the other plant classes.

\subsection{Overall Structure}

Each soluble GST is, in general, active as dimer of approximately 23-30 kDa subunits of and an average length of 200-250 aminoacids [70] (Fig. 4). Sequence identity within class is typically $>40 \%$. For example, sequence identity within tau class GSTs is shown in Fig. (5a). Interclass identities are significantly lower, usually $<20 \%$ in plants (Fig. 5b).
Although there is little sequence similarity between enzymes of different classes, there is significant conservation in overall structure (Fig. 6).

Each subunit adopts the same folding pattern, which is called 'GST fold', and consists of two distinct domains: the $\mathrm{N}$-terminal domain (approximately one third of the protein sequence), consisting of $\beta$-strands and $\alpha$-helices as secondary structure elements, usually $\beta \alpha \beta \alpha \beta \beta \alpha$, similar to the thioredoxin fold $[63,64,71]$ and the all helical $\mathrm{C}$-terminal domain composed of $\alpha$-helices arranged in a right-handed spiral (Fig. 4) $[23,72,73]$. Each subunit has an independent active site, consisting of two regions: a GSH binding site (G-site) in the $\mathrm{N}$-terminal domain and a xenobiotic (hydrophobic) substrate binding site (H-site) in the C-terminal domain [19,65,66,68,69,74] (Fig. 4a,c).

\subsection{Interactions Between Subunits}

The interactions that are involved in assembling the quaternary structure of GSTs include salt bridges, hydrogen bonds, hydrophilic and hydrophobic interactions, including a lock-and-key motif that physically anchors the two subunits together [75-77]. The lock-and-key motif is a common feature of GSTs of the tau, phi, alpha, mu and pi classes $[67,75,76]$. Only subunits with the same interfacing type appear to be compatible for dimerization. Subunits from different classes of GST are not able to dimerize because of the incompatibility of the interfacial residues $[78,79]$.

\subsection{GSH Binding Site (G-site)}

In each monomer the G-site is located in a polar region, formed by the beginning of helices $\mathrm{H} 1, \mathrm{H} 2$, and $\mathrm{H} 3$ in the $\mathrm{N}$ terminal domain, (Figs. 4A, 7) [68]. The G-site contains specific residues critical for GSH binding and catalytic activity. In particular, a highly conserved, catalytically essential Ser of the tau (Ser13 in GmGSTU4-4) [68,80], phi, zeta, and theta classes plant and of insect delta class GSTs and Tyr of the mammalian alpha, mu, pi classes GSTs have a crucial role in the mechanism of GSH activation [6]. The Ser/Tyr hydroxyl group acts as hydrogen bond donor to the thiol group of GSH, contributing to stabilization of reactive thiolate anion which is the nucleophile group for the electrophilic substrate [72,81]. GSTs that belong to the, omega,

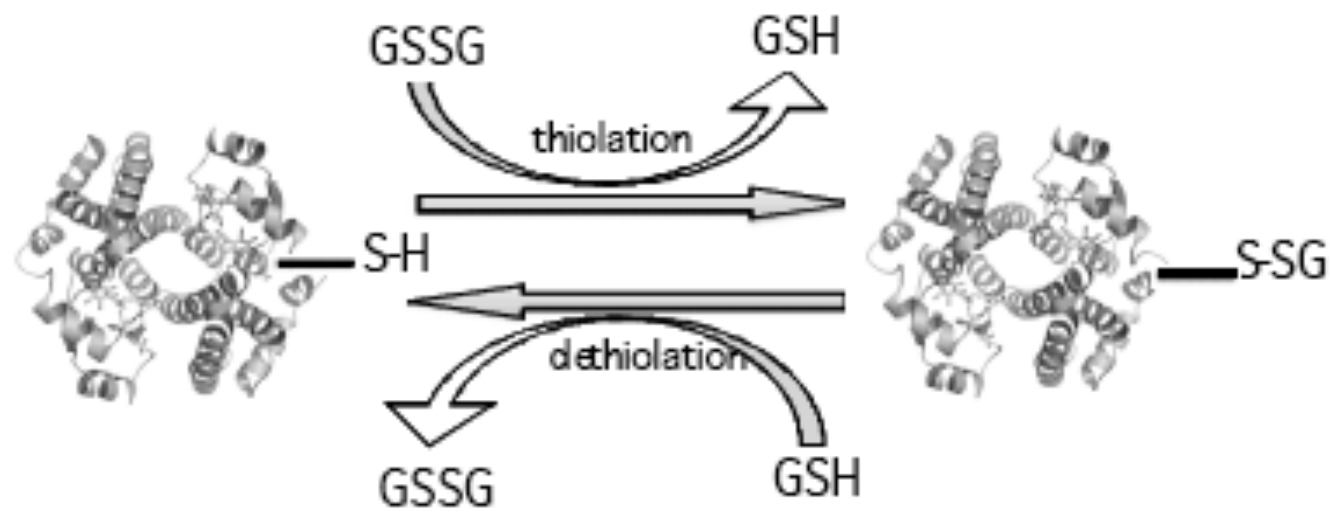

Fig. (3). Thioltransferase activity plays regulatory and protective role through reversible thiolation and dethiolation reactions. 
A

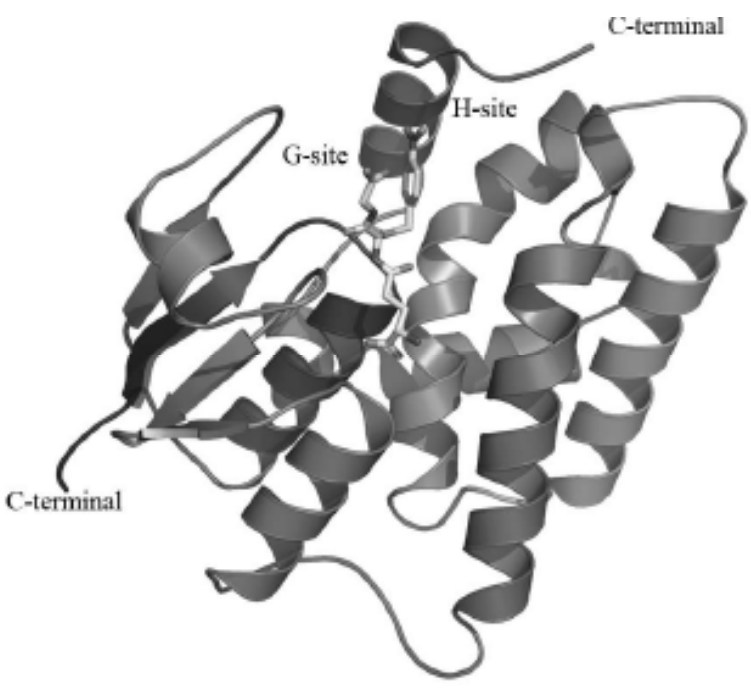

B

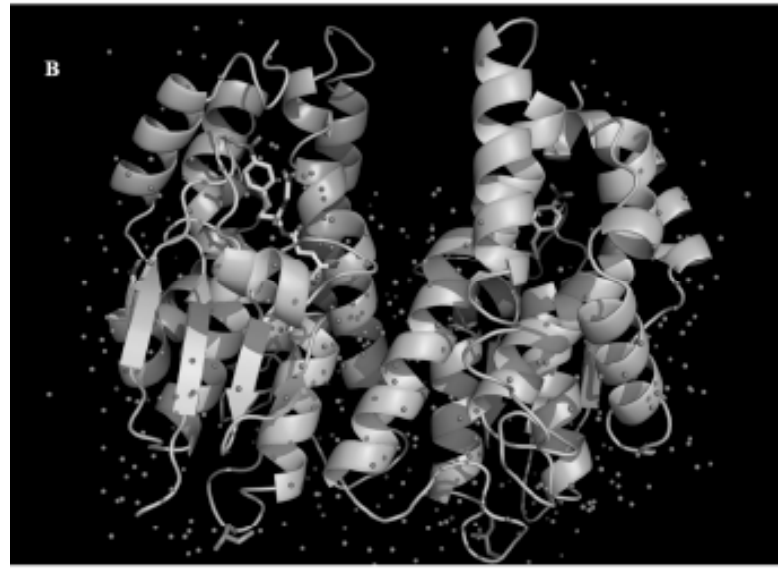

C

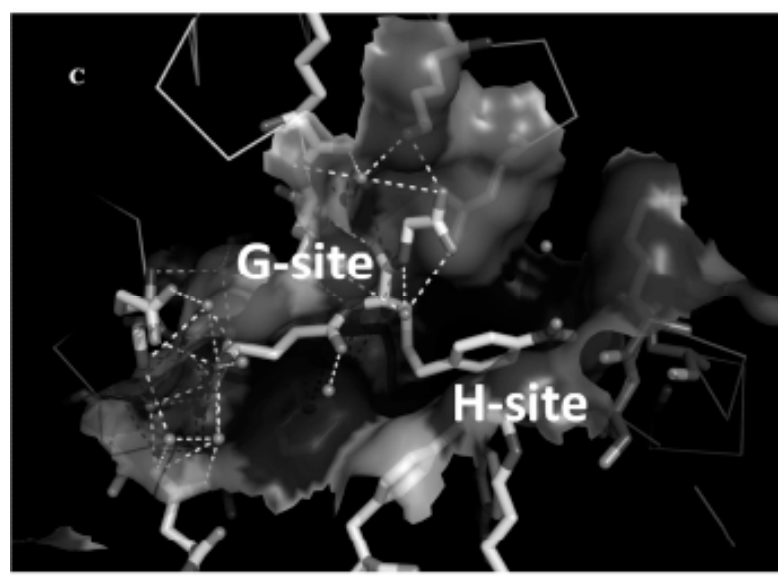

Fig. (4). A cartoon representation of the tau class GmGSTU4-4 monomer (A), dimer (B) and the substrate binding site (C). Secondary structure elements and the location of G- and $\mathrm{H}$-site are labelled. The water molecules are represented by spheres. The bound inhibitor S-(p-nitrobenzyl)-glutathione (Nb-GSH) is shown in a stick representation. The figures were produced using PyMol.

beta and lambda classes contain instead of Ser/Tyr, a catalytically essential Cys, which is involved in forming a mixed disulfide with GSH [9].

The analysis of crystal structures of soluble GSTs clearly demonstrates that, several active-site residues and a functionally conserved electron-sharing network contributes to the formation and stabilization of the thiolate anion. Amino acids mainly with positive charges for instance $\operatorname{Arg} 18(\alpha-$ helix H1) located at the bottom of the G-site, which is conserved among all tau GST sequences, although not involved directly in the formation of the G-site, seems to have an indirect role in GSH binding, and in stabilization of G-site architecture through a network of hydrogen bonds and electrostatic interactions [68].

\subsection{Electrophilic Binding Site (H-Site)}

The $\mathrm{H}$-site is composed of non-conserved residues from the C-terminal domain (Figs. 4 and 7B). In general, the $\mathrm{H}$ site of GSTs exhibits a low degree of sequence identity that determines substrate specificity (Fig. 5A). For example, the $\mathrm{H}$-site of GmGSTU4-4 is typically hydrophobic, and is built predominantly by hydrophobic residues from the C-terminal domain: helix H4a, (Tyr107, Arg111), helix H6 (Trp163) helix H9 (Phe208, Leu212, Lys215 and Leu216), and Phe10 and Leu37 from the $\mathrm{N}$-terminal domain $[68,69]$.

\subsection{Ligand Binding Site (L-Site)}

In addition to their catalytic function GSTs act as ligandbinding proteins and bind hydrophobic molecules (azo-dyes, bilirubin, heme, polycyclic aromatic hydrocarbons, steroids, thyroid hormones, plant hormones and flavonoids) in a nonsubstrate manner into a distinct site. This site is termed Lsite $[7,68,82-87]$.

Little information is available about the exact localization and the nature of the L-site in GSTs. Variation in the location of L-site between different GST isoenzymes is a wellknown feature of GSTs. For example, the L-site in GmGSTU4-4 was found to bind the molecule (4nitrophenyl) methanethiol [68] and is located in a hydrophobic surface pocket formed by Trp11, Arg20, Tyr30, Tyr32, Leu199 and Pro200 (Fig. 8). The main binding residues (Trp11, Arg20, Tyr30 and Tyr32) are, in general, conserved within the tau GST family (Fig. 5A). On the other hand, the L-site of GST from Schistosoma japonica [82] is located at the dimer interface. In the case of the Arabidopsis enzyme [88], the L-site is located next to the G-site between the side chains of helices $\alpha 3$ " $/ \alpha 3$ ", and $\alpha 5$ ", whereas the L-site of the human pi class GST and the maize GST I is located into the H-site $[83,86]$.

The precise role of L-site is unclear. However, it has been proposed that binding of non-substrate ligands to GST prevents modification (e.g. degradation, oxidation) of the molecules in vivo. Another possibility is that GST prevents cellular damage that may be caused by cytotoxic and genotoxic compounds. The other possibility is that binding to Lsite may help to the delivery of the ligands to specific cellular protein receptors or compartments $[83,84,86,68]$. Lu and Atkins (2004) have demonstrated the possible antioxidant role for the ligandin activity of GSTs [29]. More recently, Dixon and Edwards have shown that GSTUs from Arabidopsis thaliana are able to bind tightly thioester of faty acids 
A

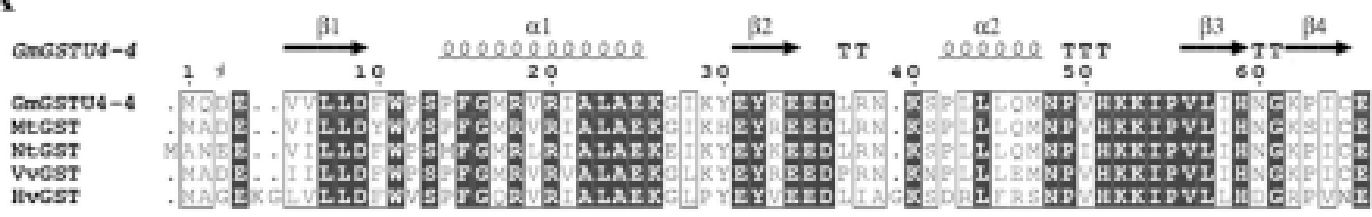

$\alpha 3$

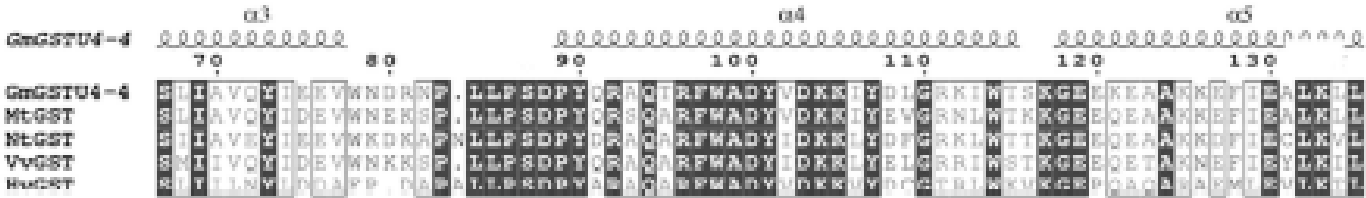

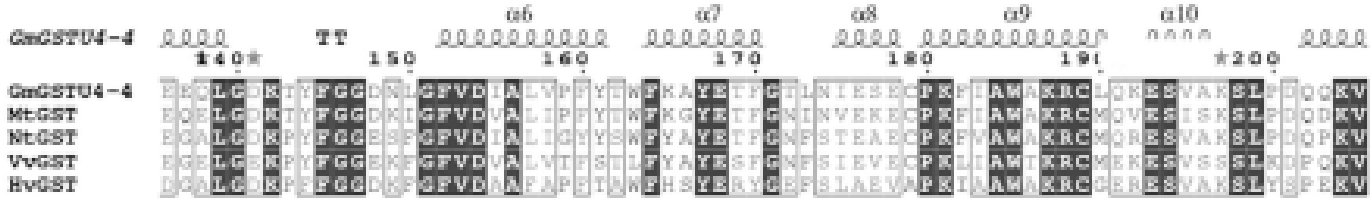
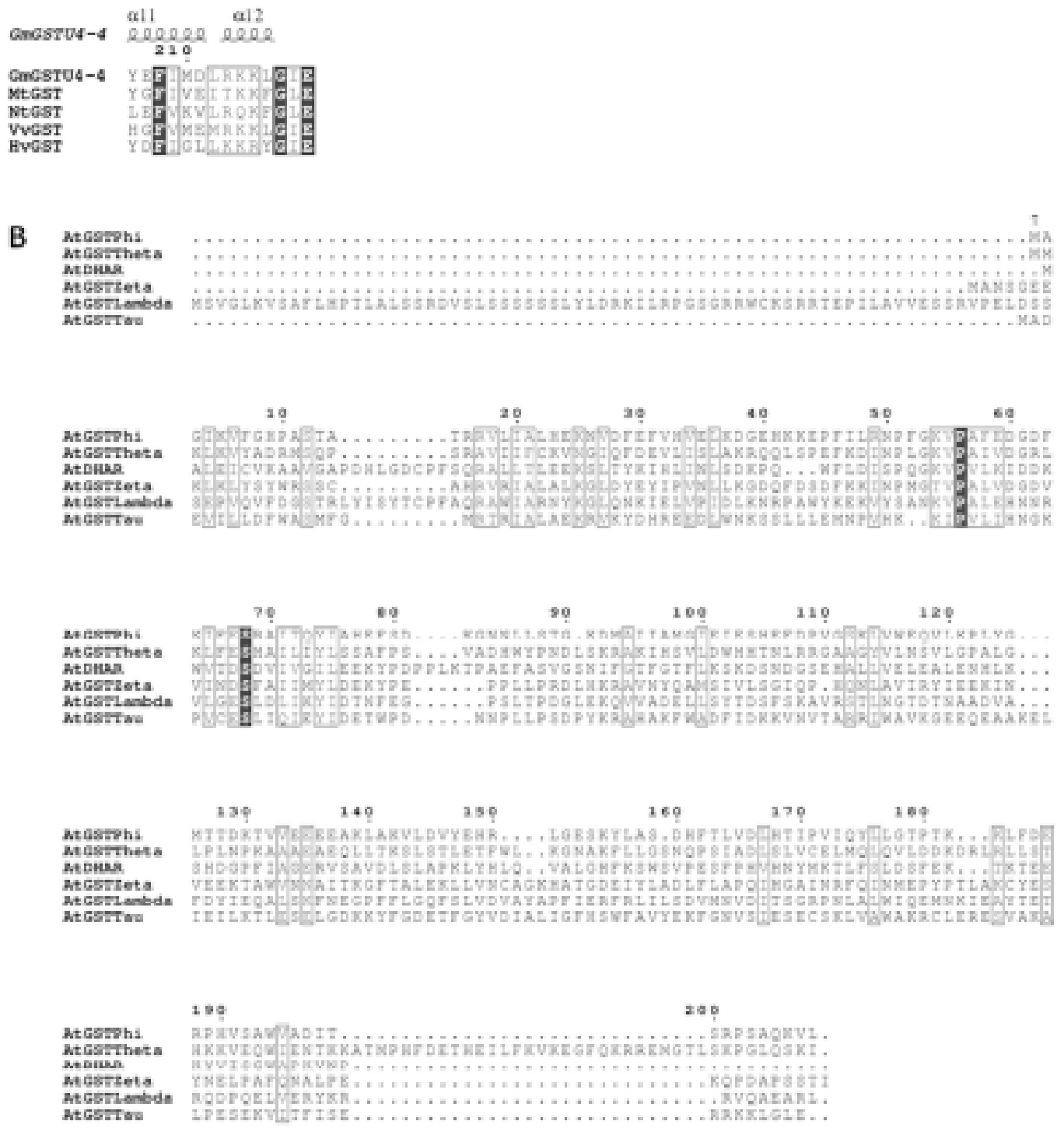
Fig. (5). Contd....

C

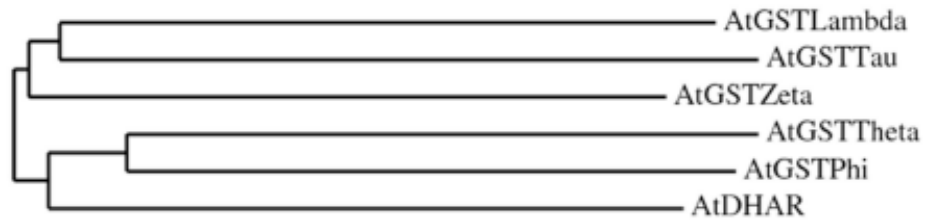

0.2

Fig. (5). A: Sequence alignment of members of the tau family of GSTs compared with the secondary structure of GmGSTU4-4 (PDB code 2VO4) produced using ESPript (http://espript.ibcp.fr/ESPript/ESPript/). GmGSTU4-4 numbering is shown above the alignment. Alpha helices and beta strands are represented as helices and arrows, respectively, and beta turns are marked with TT. Conserved areas are shown shaded. A column is framed, if more than $70 \%$ of its residues are similar according to physico-chemical properties. This sequence alignment was created using the following sequences (NCBI accession numbers are in parentheses): GmGSTU4-4: Glycine max (AAC18566), NtGST: Nicotiana tabacum (CAA39707), VvGST: Vitis vinifera (XP_002263395), MtGST: Medicago truncatula (ACJ85907), HvGST: Hordeum vulgare (ABI18247). B: Sequence alignment of representative members of the Arabidopsis thaliana GST family (phi, theta, DHAR, lambda and tau). Conserved areas are shown shaded. A column is framed, if more than $70 \%$ of its residues are similar according to physico-chemical properties. This sequence alignment was created using the following sequences (NCBI accession numbers are in parentheses): AtGST Phi (NP_171792); AtGST theta (NP_198937); AtDHAR (Q9FWR4); AtGST zeta (Q9ZVQ3); AtGST tau (AAS76278); AtGST lambda (NP_191064). C: Phylogenetic analysis of representative members of the Arabidopsis thaliana GST family (phi, theta, DHAR, lambda and tau) (TreeDyn program run at http://www.phylogeny.fr/).

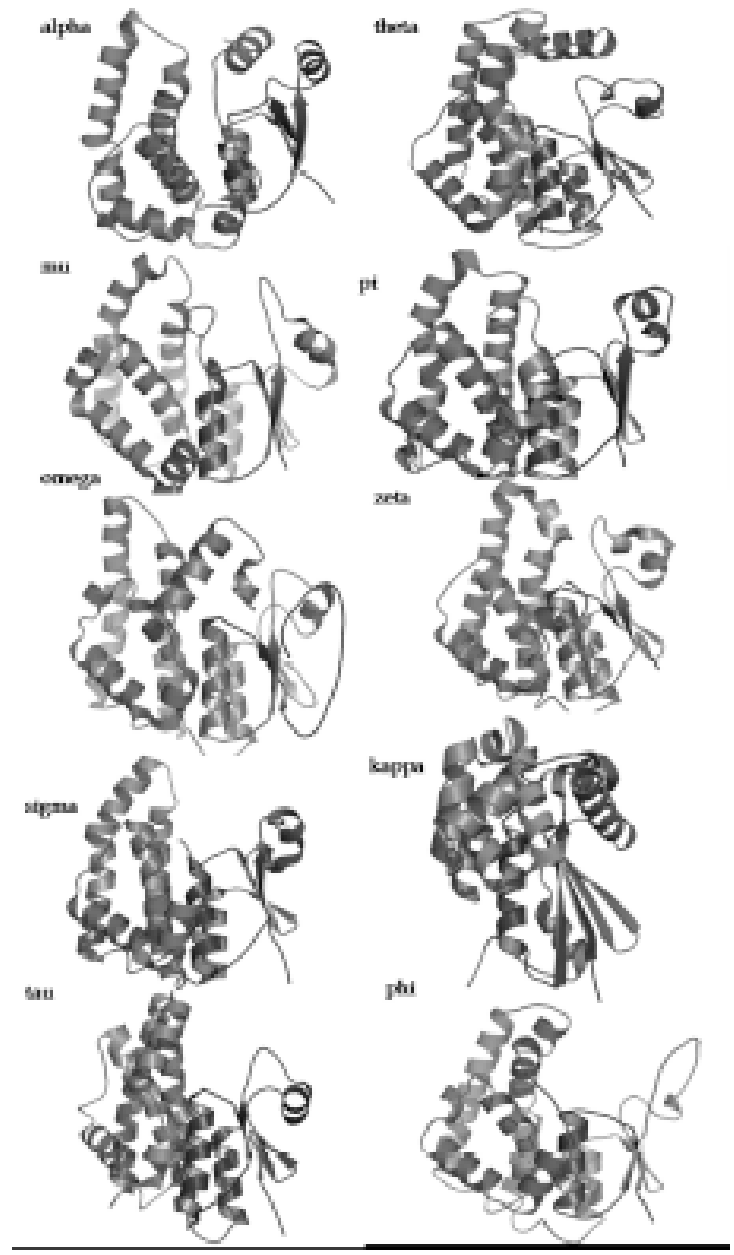

Fig. (6). Ribbon representations of the structures of the GST classes: alpha (PDB code: 1gse), mu (PDB code: 1hna), pi (PDB code: 1glp), theta (PDB code: 1ljr), zeta (PDB code: 1fw1), omega (PDB code: 1eem), sigma (PDB code: 1mou), kappa (PDB code: 1yzx), phi (PDB code: 1aw9), tau (PDB code: 1gwc). The figure was produced using PyMol. 
A

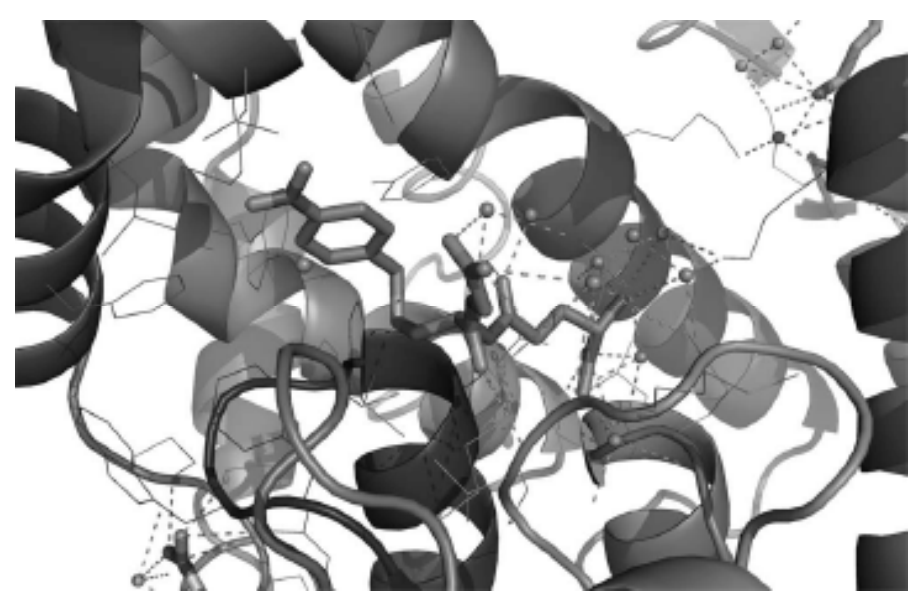

B

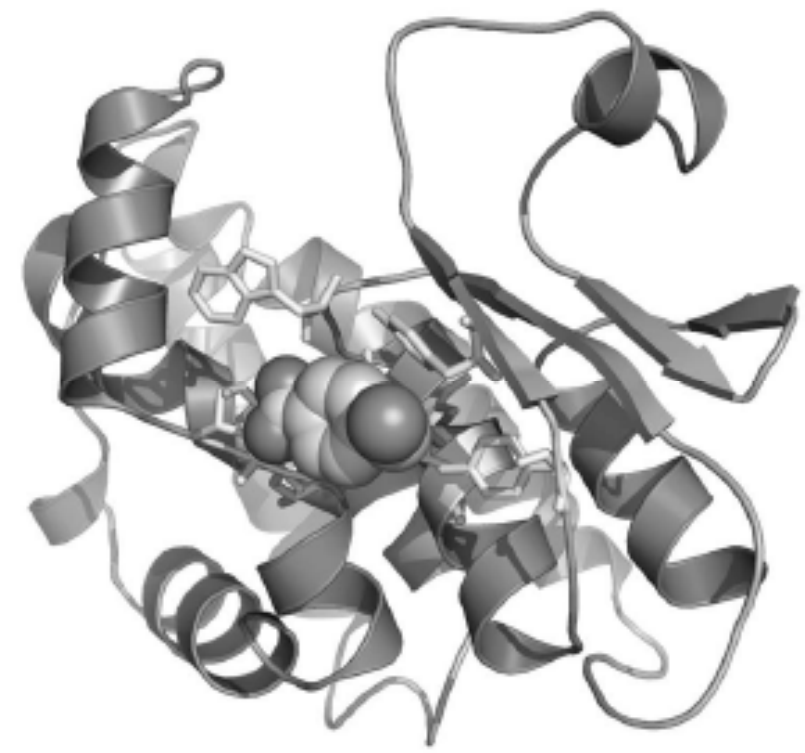

Fig. (7). Cartoon representation of the G- and H-site of GmGSTU4-4 with the inhibitor S-(p-nitrobenzyl)-glutathione. Amino acid side chains that contribute directly to $\mathrm{G}$ and $\mathrm{H}$-site formation are shown in a stick representation. The figure was produced using PyMol.

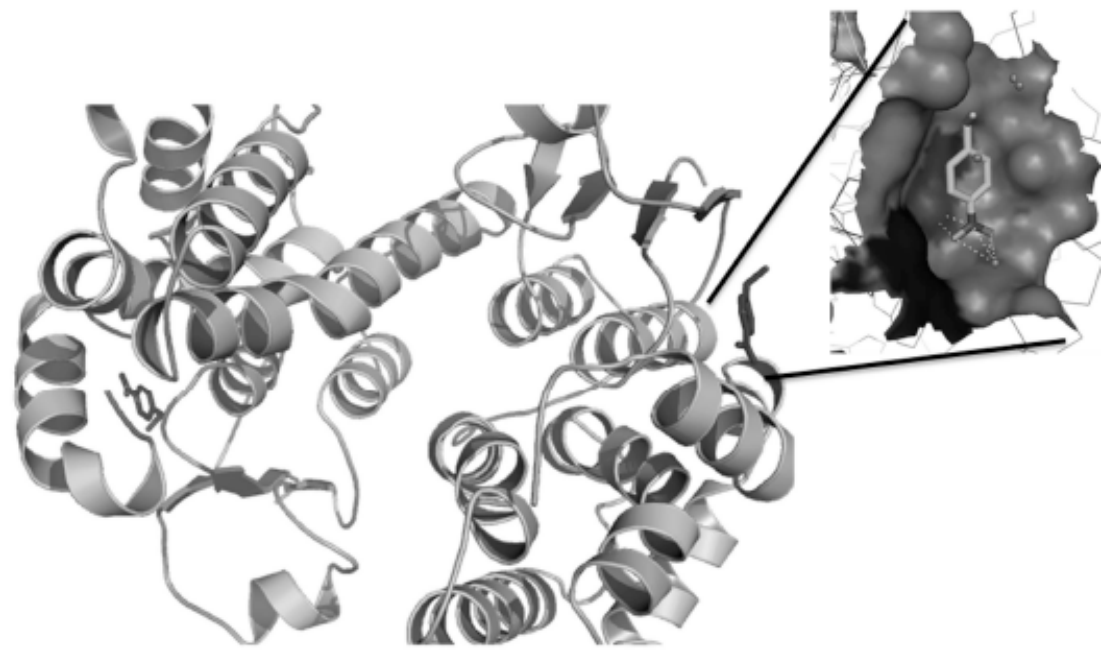

Fig. (8). A representation of the putative L-site of GmGSTU4-4 with the ligand (4-nitrophenyl)-methanethiol. The ligand (4-nitrophenyl)methanethiol is represented as a stick. The figure was produced using PyMol. 
with varied chain length $\left(\mathrm{C}_{(6)}\right.$ to $\left.\mathrm{C}_{(18)}\right)$, oxygen content, and desaturation, with $\mathrm{K}_{(\mathrm{d})}$ approximately $1 \mu \mathrm{M}$ [89]. The strong and binding of various fatty acids by each GSTU and the conservation in binding observed in the different hosts suggest that GSTUs have selective roles in binding and conjugating these unstable metabolites in vivo. In addition, the same group of researchers has shown that the ability of GSTs to act as ligand binding proteins of porphyrins in vitro [90] results in highly specific interactions with porphyrinogen intermediates, which can be demonstrated in both plants and bacteria in vivo [91].

In conclusion, the plant GST family of enzymes belongs to the thioredoxin superfamily classified by the common GSH binding domain-adopted thioredoxin fold. The GST family represents a group of catalysts with multiple roles many of which are important in counteracting biotic and abiotic stress. These roles can be relevant to maintaining cellular homeostasis as well as in the direct detoxification of toxic compounds. The detoxification roles of GSTs arise for their ability to catalyze the conjugation of GSH to a large number of electrophilic molecules. The antioxidant catalytic function of GSTs is exhibited through peroxidase, thioltransferase and dehydroascorbate reductase activity. Further analysis and study of this protein family will inevitable reveal many examples of functional and catalytic diversification and will highlight the importance of these enzymes in the protection against the oxidative stress and in other cellular processes.

\section{ACKNOWLEDGMENT}

The authors thank the Ministry of Education, Lifelong Learning and Religious Affairs for the financial assistance provided. This work was performed within the program HERACLITUS II, co-funded by the European UnionEuropean Social Fund \& National Resources.Thegrant was awarded to EC and NEL.

\section{ABBREVIATIONS}

$\begin{array}{lll}\text { CDNB } & = & \text { 1-chloro-2,4-dinitrobenzene } \\ \text { GSH } & =\text { Glutathione } \\ \text { GST } & =\text { Glutathione transferase } \\ \text { G-site } & =\text { GSH binding site } \\ \text { GPx } & =\text { Glutathione peroxidase } \\ \text { H-site } & =\text { Hydrophobic binding site; S-(p- } \\ \text { Nb-GSH } & =\text { Sec, Selenocysteine } \\ \text { ROS } & =\text { Reactive Oxygen Species }\end{array}$

\section{REFERENCES}

[1] Marrs KA. The functions and regulation of glutathione Stransferases in plants. Annu Rev Plant Physiol Plant Mol Biol 1996; 47: 127-58.

[2] McGonigle B, Keeler SJ, Lau SM, Koeppe MK, O'Keefe DP. A genomics approach to the comprehensive analysis of the glutathione S-transferase gene family in soybean and maize. Plant Physiol 2000; 124: 1105-20.

[3] Edwards R. and Dixon DP. Plant glutathione transferases. Methods Enzymol 2005; 401: 169-186.
[4] Chronopoulou EG, Labrou NE. Glutathione transferases: emerging multidisciplinary tools in red and green biotechnology. Recent Pat Biotechnol 2009; 3: 211-23.

[5] Dixon DP, Skipsey M, Edwards R. Roles for glutathione transferases in plant secondary metabolism. Phytochemistry 2010; 71: $338-50$.

[6] Sheehan D, Meade G, Foley VM, Dowd CA. Structure, function and evolution of glutathione transferases: implications for classification of non-mammalian members of an ancient enzyme superfamily. Biochem J 2001; 360: 1-16.

[7] Droog F. Plant Glutathione S-Transferases, a Tale of Theta and Tau. J Plant Growth Regul 1997; 16: 95-107.

[8] Edwards R. Characterisation of glutathione transferases and glutathione peroxidases in pea (Pisum sativum). Physiol Plant 1996; 98: 594-604.

[9] Dixon DP, Davies BG, Edwards R. Functional divergence in the glutathione transferase superfamily in plants: identification of two classes with putative functions in redox homeostasis in Arabidopsis thaliana. J Biol Chem 2002; 277: 30859-69.

[10] Dixon DP, Lapthorn A. Edwards R. Protein family review: Plant glutathione transferases. Genome Biol 2002; 3: 3004.1-3004.10.

[11] Runarsdottir A, Mannervik B. A novel quasi-species of glutathione transferase with high activity towards naturally occurring isothiocyanates evolves from promiscuous low-activity variants. J Mol Biol 2010; 401: 451-64.

[12] Balogh LM, Le Trong I, Kripps KA, et al. Substrate specificity combined with stereopromiscuity in glutathione transferase A4-4dependent metabolism of 4-hydroxynonenal. Biochemistry. 2010; 49:1541-8.

[13] Kurtovic S, Mannervik B. Identification of emerging quasi-species in directed enzyme evolution. Biochemistry 2009; 48: 9330-9.

[14] Skopelitou K, Platis D, Axarli I, Labrou, NE. Glutathione transferases in drug discovery and development: towards safer and efficacious drugs, In "Frontiers in Drug, Design and Discovery ", Bentham Science Publishers, 2009; 4: 23-42.

[15] Hou L, Honaker MT, Shireman LM, Balogh LM, Roberts AG, Ng KC, Nath A, Atkins WM. Functional promiscuity correlates with conformational heterogeneity in A-class glutathione S-transferases. Biol Chem 2007; 282: 23264-23274.

[16] Cummins I, Cole DJ, Edwards R. Purification of multiple glutathione transferases involved in herbicide detoxification from wheat (Triticum aestivum L.) treated with the safener fenchlorazole-ethyl. Pestic Biochem Physiol 1997; 59: 35-49.

[17] Roxas VP, Smith RK, Jr. Allen ER, Allen RD. Overexpression of glutathione S-transferase/glutathione peroxidase enhances the growth of transgenic tobacco seedlings during stress. Nat Biotechnol 1997; 15: 988-91.

[18] Kampranis SC, Damianova R, Atallah M, et al. A novel plant glutathione S-transferase/peroxidase suppresses bax lethality in yeast. J Biol Chem 2000; 275: 29207-29216.

[19] Thom R, Cummins I, Dixon DP, Edwards R, Cole DJ, Lapthorn AJ. Structure of a tau class glutathione S-transferase from wheat active in herbicide detoxification. Biochemistry 2002; 41: 7008-20.

[20] Cho HY, and Kong KH. Study on the biochemical characterization of herbicide detoxification enzyme, glutathione S-transferase. Biofactors 2007; 30: 281-287.

[21] Frova C. The plant glutathione transferase gene family: genomic structure, functions, expression and evolution. Physiol Plant 2003; 119: 469-479.

[22] Mannervik B. Glutathione peroxidase, Methods Enzymol 1985; 113: 490-495.

[23] Mannervik B, Danielson UH. Glutathione transferases-structure and catalytic activity. CRC Crit Rev Biochem 1988; 23: 283-337.

[24] Cummins I, Cole DJ, Edwards R. A role for glutathione transferases functioning as glutathione peroxidases in resistance to multiple herbicides in black-grass. Plant J 1999; 18: 285-92.

[25] Dixon DP, Cummins I, Cole DJ, Edwards R. Glutathione mediated detoxification systems in plants. Curr Opini Plant Biol 1998; 1: 258-66.

[26] Edwards R, Dixon DP, Walbot V. Plant glutathione S-transferases: enzymes with multiple functions in sickness and in health. Trends Plant Sci 2000; 5: 193-8.

[27] Huberts DH, van der Klei IJ. Moonlighting proteins: an intriguing mode of multitasking. Biochim Biophys Acta. 2010; 1803: 520-5. 
[28] Jeffery CJ. Moonlighting proteins- an update. Mol Biosyst 2009; 5: 345-50.

[29] Lu WD, and Atkins WA. Novel Antioxidant Role for Ligandin Behavior of glutathione S-Transferases: Attenuation of the Photodynamic Effects of Hypericin. Biochemistry 2004; 43: 1276112769.

[30] Ginsberg G, Smolenski S, Hattis D, Guyton KZ, Johns DO, Sonawane B. Genetic Polymorphism in Glutathione Transferases (GST): Population distribution of GSTM1, T1, and P1 conjugating activity. J Toxicol Environ Health B Crit Rev 2009;12:389-439.

[31] Allocati N, Federici L, Masulli M, Di Ilio C. Glutathione transferases in bacteria. FEBS J 2009; 276: 58-75.

[32] Wu Y, Fan Y, Xue B, et al. Human glutathione S-transferase P1-1 interacts with TRAF2 and regulates TRAF2-ASK1 signals. Oncogene 2006; 25: 5787-800.

[33] Laborde E. Glutathione transferases as mediators of signaling pathways involved in cell proliferation and cell death. Cell Death and Differentiation 2010 17:1373-80.

[34] Gancedo C, and Flores C-L. Moonlighting Proteins in Yeasts. Microbiology and molecular biology. 2008; 72: 197-210

[35] Lian HY, Jiang Y, Zhang H, Jones GW, Perrett S. The yeast prion protein Ure2: structure, function and folding. Biochim Biophys Acta 2006; 1764: 535-45.

[36] Grill E, Winnacker EL, Zenk MH. Phytochelatins: the principle of heavy-metal complexing peptides of higher plants. Science 1985; 230: 674-676

[37] Freeman JL, Persans MW, Nieman K, et al. Increased glutathione biosynthesis plays a role in nickel tolerance in Thlaspi nickel hyperaccumulators. Plant Cell 2004;16: 2176-2191.

[38] Noctor G, Veljovic-Jovanovic S, Foyer CH. Peroxide processing in photosynthesis: antioxidant coupling and redox signaling. Proc $\mathrm{R}$ Soc Lond B Biol Sci 2000; 355: 1465-65.

[39] Tausz M, Sircelj H, Grill D. The glutathione system as a stress marker in plant ecophysiology: is a stress-response concept valid? J Exp Bot 2004; 55: 1855-62.

[40] Rouhier N, Jacquot JP. The plant multigenic family of thiol peroxidases. Free Radic Biol Med 2005; 38: 1413-21.

[41] Foyer CH, Noctor G. Oxidant and antioxidant signaling in plants: a re-evaluation of the concept of oxidative stress in a physiological context. Plant Cell Environ 2005; 28: 1056-71.

[42] Foyer CH, Halliwell B. The presence of glutathione and glutathione reductase in chloroplasts: a proposed role in ascorbic acid metabolism. Planta 1976; 133: 21-5.

[43] Noctor G, Foyer CH. Simultaneous measurement of foliar glutathione, $\gamma$-glutamylcysteine and amino acids by high-performance liquid chromatography: comparison with two other assay methods for glutathione. Anal Biochem 1998; 264: 98-110.

[44] Desikan R, Hancock J, Neill S. In: Smirnoff N, Ed. Antioxidants and reactive oxygen species in plants. Blackwell Publishing Ltd. 2005; 169-96.

[45] Bartling D, Radzio R, Steiner U, Weiler EW. A glutathione Stransferase with glutathione-peroxidase activity from Arabidopsis thaliana. Molecular cloning and functional characterization. Eur J Biochem 1993; 216: 579-86.

[46] Moons A. Regulatory and functional interactions of plant growth regulators ant plant Glutathione S-transferases (GSTs). Vitamins and Hormones 2005; 72: 155-202.

[47] Filomeni G, Rotilio G, Ciriolo MR. Glutathione disulfide induces apoptosis in U937 cells by a redox-mediated p38 MAP kinase pathway. FASEB J 2003; 17: 64-6.

[48] Circu ML, Aw TY. Glutathione and apoptosis. Free Radic Res 2008; 42: 689-706.

[49] Schafer FQ, Buettner GR. Redox environment of the cell as viewed through the redox state of the glutathione disulfide/glutathione couple. Free Radic Biol Med 2001; 30: 1191-212

[50] Sabeh F, Wright T, Norton SJ. Purification and characterization of a glutathione peroxidase from the Aloe vera plant. Enzyme Protein 1993; 47: 92-98.

[51] Eshdat Y, Holland D, Faltin Z, Ben-Hayyim G. Plant glutathione peroxidases. Physiol Plant 1997; 100: 234-40.

[52] Milla MAR, Maurer A, Huete AR, Gustafson JP. Glutathione peroxidase genes in Arabidopsis are ubiquitous and regulated by abiotic stresses through diverse signalling pathways. Plant J 2003; 36: $602-15$.
[53] Navrot N, Collin V, Gualberto J, et al. Plant glutathione peroxidases are functional peroxiredoxins distributed in several subcellular compartments and regulated during biotic and abiotic stresses. Plant Physiol 2006; 142: 1364-79.

[54] Edwards R, Dixon DP. Plant glutathione transferases. Methods Enzymol 2005; 401: 169-86.

[55] Skipsey M, Andrews CJ, Townson JK, Jepson I, Edwards R. Substrate and thiol specificity of a stress-inducible glutathione transferase from soybean. FEBS Lett 1997; 409: 370-4.

[56] Wagner U, Edwards R, Dixon DP, Mauch F. Probing the Diversity of the Arabidopsis glutathione S-Transferase Gene Family. Plant Mol Biol 2002; 49: 515-32.

[57] Wang W, Ballatori N. Endogenous Glutathione Conjugates: Occurrence and Biological Functions. Pharmacological Reviews 1998; 50: $335-56$

[58] Mieyal JJ, Gallogly MM, Qanungo S, Sabens EA, Shelton MD. Molecular mechanisms and clinical implications of reversible protein S-glutathionylation. Antioxid Redox Signal 2008; 10: 1941-88.

[59] Dafre AL, Sies H, Akerboom T. Protein S-thiolation and regulation of microsomal glutathione transferase activity by the glutathione redox couple. Arch Biochem Biophys 1996; 332: 288-94.

[60] Lou MF. Redox regulation in the lens. Prog Retin Eye Res 2003 22: $657-82$.

[61] Hurd TR, Costa NJ, Dahm CC, et al. Glutathionylation of mitochondrial proteins. Antioxid Redox Signal 2005; 7: 999-1010.

[62] Labrou NE, Mello LV, Clonis YD. Functional and structural roles of the glutathione-binding residues in maize (Zea mays) glutathione S-transferase I. Biochem J 2001; 358: 101-10.

[63] Martin JL. Thioredoxin-a fold for all reasons, Structure 1995; 3: 245-250.

[64] Wilce MC, Parker MW. Structure and function of glutathione S transferases. Biochim Biophys Acta 1994; 1205: 1-18.

[65] Neuefeind T, Huber R, Dasenbrock H, Prade L, Bieseler B. Crystal structure of herbicide-detoxifying maize glutathione S-transferase-I in complex with lactoylglutathione: evidence for an induced-fit mechanism. J Mol Biol 1997; 274: 446-53.

[66] Neuefeind T, Huber R, Reinemer P, et al. Cloning, sequencing, crystallization and X-ray structure of glutathione S-transferase-III from Zea mays var. mutin: a leading enzyme in detoxification of maize. J Mol Biol 1997; 274: 577-87.

[67] Thom R, Dixon DP, Edwards R, Cole DJ, Lapthorn AJ. The structure of a zeta class glutathione S-transferase from Arabidopsis thaliana: characterisation of a GST with novel active-site architecture and a putative role in tyrosine catabolism. J Mol Biol 2001; 308: 949-62.

[68] Axarli, I, Dhavala, P, Papageorgiou, AC, Labrou, NE. Crystallographic and Functional Characterization of the Fluorodifeninducible Glutathione Transferase from Glycine max Reveals an Active Site Topography Suited for Diphenylether Herbicides and a Novel L-site. J Mol Biol 2009; 385: 984-1002.

[69] Axarli I, Dhavala P, Papageorgiou AC, Labrou NE. Crystal structure of Glycine max glutathione transferase in complex with glutathione: investigation of the mechanism operating by the Tau class glutathione transferases. Biochem J 2009; 422: 247-56

[70] Edwards R, Dixon DP, Walbot, V. Plant glutathione S-transferases: enzymes with multiple functions in sickness and in health. Trends Plant Sci 2000; 5: 193-8

[71] Katti SK, LeMaster DM, Eklund H. Crystal structure of thioredoxin from Escherichia coli at $1.68 \AA$ A resolution. J Mol Biol 1990; 212: 167-84.

[72] Armstrong, RN. Structure, catalytic mechanism, and evolution of the glutathione transferases. Chem Res Toxicol 1997; 10: 2-18.

[73] Oakley AJ. Glutathione transferases: new functions. Curr Opin Struct Biol 2005; 15: 716-23.

[74] Prade L, Huber R, Bieseler B. Structures of herbicides in complex with their detoxifying enzyme glutathione S-transferase - explanations for the selectivity of the enzyme in plants. Structure 1998; 6: 1445-52.

[75] Sayed Y, Wallance LA, Dirr HW. The hydrophobic lock-and-key intersubunit motif of glutathione transferase A1-1: implications fo catalysis, ligandin function and stability. FEBS Lett 2000; 465: 169-72.

[76] Hegazy UM, Mannervik B, Stenberg GJ. Functional role of the lock and key motif at the subunit interface of glutathione transferase P1-1. J Biol Chem 2004; 279: 9586-9596. 
[77] Vargo MA, Nguyen L, Colman RF. Subunit interface residues of glutathione S-transferase A1-1 that are important in the monomerdimer equilibrium. Biochemistry 2004; 43: 3327-35.

[78] Hayes, JD, and Pulford DJ. The glutathione S-transferase supergene family: regulation of GST and the contribution of the isoenzymes to cancer chemoprotection and drug resistance. Crit Rev Biochem Mol Biol 1995; 30: 445-600.

[79] Hayes JD, Flanagan JU, Jowsey IR. Glutathione transferases. Annu Rev Pharmacol Toxicol 2005; 45: 51-88.

[80] Axarli I, Georgiadou C, Dhavala P, Papageorgiou AC, Labrou NE. Investigation of the role of conserved residues Ser13, Asn48 and Pro49 in the catalytic mechanism of the tau class glutathione transferase from Glycine max. Biochim Biophys Acta. 2010; 1804: 662-

[81] Dirr HW, Reinemer P, Huber R. X-ray crystal structures of cytosolic glutathione S-transferases. Implications for protein architecture, substrate recognition and catalytic function. Eur J Biochem 1994; 220: 645-61.

[82] McTigue MA, Williams DR, Tainer JA. Crystal structures of a schistosomal drug and vaccine target: glutathione S-transferase from Schistosoma japonica and its complex with the leading antischistosomal drug praziquantel. J Mol Biol 1995; 246: 21-7.

[83] Oakley AJ, Lo Bello M, Nuccetelli M, Mazzetti AP, Parker MW. The ligandin (non-substrate) binding site of human Pi class glutathione transferase is located in the electrophile binding site $(\mathrm{H}-$ site). J Mol Biol 1999; 291: 913-26.
[84] Mueller L, Goodman CD, Silady RA, Walbot V. AN9, a petunia glutathione S-transferase required for anthocyanin sequestration, is a flavonoid-binding protein. Plant Physiol 2000; 123: 1561-70.

[85] Smith AP, Nourizadeh SD, Peer WA, et al. Arabidopsis AtGSTF2 is regulated by ethylene and auxin, and encodes a glutathione Stransferase that interacts with flavonoids. Plant J 2003; 36: 433-42.

[86] Axarli IA, Rigden DJ, Labrou NE. Characterization of the ligandin site of maize glutathione S-transferase I. Biochem J 2004; 382: 885-93.

[87] Hayeshi R, Chinyanga F, Chengedza S, Mukanganyama, S. Inhibition of human glutathione transferases by multidrug resistance chemomodulators in vitro. J Enzyme Inhib Med Chem 2006; 21: 581-7.

[88] Reinemer P, Prade L, Hof P, et al. Three-dimensional structure of glutathione S-transferase from Arabidopsis thaliana at $2.2 \AA$ resolution: structural characterization of herbicide-conjugating plant glutathione S-transferases and a novel active site architecture. J Mol Biol 1996; 255: 289-309.

[89] Dixon DP, Edwards R. Selective binding of glutathione conjugates of fatty acid derivatives by plant glutathione transferases. J Biol Chem. 2009; 284:21249-56.

[90] Lederer B, Böger P. A ligand function of glutathione S-transferase. Z Naturforsch C. 2005 60:166-71.

[91] Dixon DP, Lapthorn A, Madesis P, Mudd EA, Day A, Edwards R. Binding and glutathione conjugation of porphyrinogens by plant glutathione transferases. J Biol Chem. 2008; 283: 20268-76. 